\title{
COHERENT TUNNELING IN A SEMICONDUCTOR SYSTEM: DOUBLE BARRIER RESONANT-TUNNELING STRUCTURE BUILT IN THE SCHOTTKY BARRIER
}

\author{
S. D. Lin $^{1}$, C. P. Lee ${ }^{1}$, V. V. Ilchenko ${ }^{2}$ D. I. Sheka ${ }^{2}$, O. V. Tretyak ${ }^{2}$, A. M. Korol ${ }^{3}$, I. V. Nosenko ${ }^{3}$ \\ ${ }^{1}$ Department of Electronics Engineering, National Chiao-Tung University, \\ 1001 Ta Hsueh Road, Hsinchu, Taiwan, Republic of China \\ ${ }^{2}$ Faculty of Radiophysics, Taras Shevchenko National University of Kyiv, \\ 64, Volodymyrska St., Kyiv, Ukraine \\ ${ }^{3}$ Department of Physics, National University for Food Technologies, \\ 68, Volodymyrska St., Kyiv, Ukraine
}

(Received January 16, 2007)

\begin{abstract}
Resonant-tunneling processesing electrons in a system consisting of the double-barrier resonanttunneling structure built in the Schottky barrier are studied. It is shown that the coherent tunneling can take place in this system; both the transmission rates of electrons and the current-voltage characteristic are evaluated and analyzed for such a case. The theoretical results agree perfectly well with the data obtained from the especially performed experiment.
\end{abstract}

Key words: Schottky barrier, double barrier, resonant-tunneling current, transmission rates.

PACS number(s): 73.40.Gk

The problem: the issue of the mechanism of transmission of electrons - coherent or incoherent - can be realized in a specific resonant tunneling structure (RTS) was formulated a long while ago. And lot of papers have considered this problem. This is because of the obvious significance of this problem to the performance of RTS based devices. The answer depends on many factors such as degree of imperfections (in part, at interfaces), intensity of scattering of electrons (elastic and inelastic) etc.

In this paper, we consider the above mentioned problem in relation to a semiconductor system consisting of a double barrier resonant-tunneling structure (DBRTS) located in a depletion region of the Schottky barrier (the system is referred to further as RTSC, Fig. 1) [1,2]. As has been shown in references cited, a new mechanism of the arising of very steep nonlinear current-voltage characteristics (IVC) can be realized in RTSC. The density of resonant-tunneling current (RTC) has been evaluated using the known formula

$$
\begin{aligned}
j & =\frac{e m k_{\mathrm{B}} T}{2 \pi^{2} \hbar^{3}} \int_{0}^{\infty} D(E, V) \\
& \times \ln \frac{1+\exp \left[\left(E_{F}-E\right) / k_{\mathrm{B}} T\right]}{1+\exp \left[\left(E_{F}-E-e V\right) / k_{\mathrm{B}} T\right]} d E,
\end{aligned}
$$

where $k_{\mathrm{B}}$ is the Boltzmann constant, $T$ is the temperature, $e$ is an electron charge, $m$ is effective mass of an electron, $D(E, V)$ is the coefficient of transmission of electrons through the system depending on an electron energy $E, E_{F}$ is Fermi level, $V$ is an external potential. The quantity $D(E, V)$ is expressed via the rates of transparency for the depletion region $D_{s}$ and for the DBRTS $D_{r}$. If the tunneling through the DBRTS and the Schottky barrier is incoherent $D(E)$ equals the product $D_{s} D_{r}$. This approximation is correct when the mean free path of an electron in the semiconductor is less than the width of the depletion region. We call attention to the fact that electrons with the energies $E<0.1 \mathrm{eV}$ only take part in the tunneling in the structure considered - these are energies of the order of the lowest resonant level in the DBRTS for typical parameters. A dependence of the mean free path $l$ on the concentration of doping shallow impurities $n_{0}$ is shown in Fig. 2 ; this dependence is calculated using the dates on the electron mobility for various $E$ [3]. The dependence of the width of a depletion region $L=\left(\frac{2 \varepsilon \varepsilon_{0} \varphi(0)}{e^{2} n_{0}}\right)^{1 / 2}$ on $n_{0}$ is also plotted in this figure for such parameters: dielectric permittivity $\varepsilon=10.4$ (GaAs), the height of a potential barrier at the interface $\varphi(0)=0.6 \mathrm{eV}$. We see that the transmission of electrons has to be coherent in the region of concentrations $10^{17} \mathrm{~cm}^{-3}<n_{0}<10^{19} \mathrm{~cm}^{-3}$.

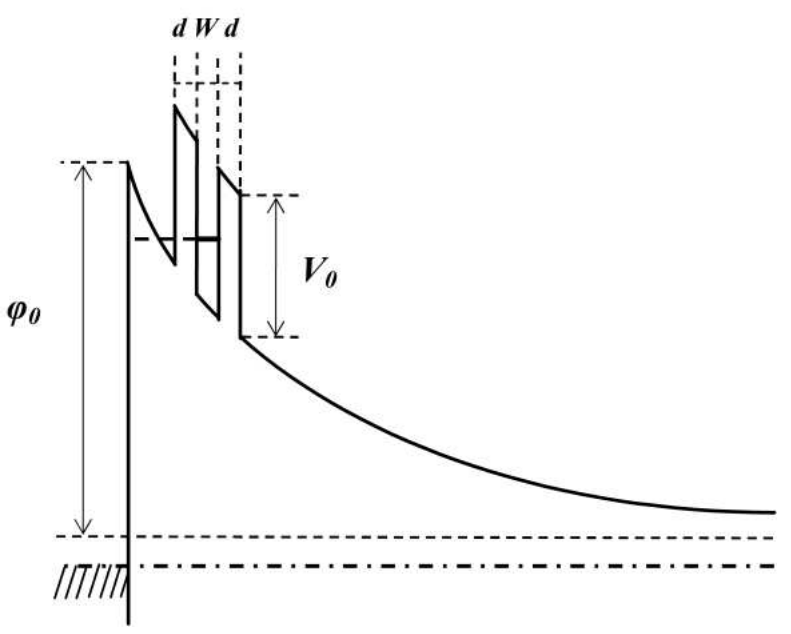

Fig. 1. Potential profile of the structure considered. 


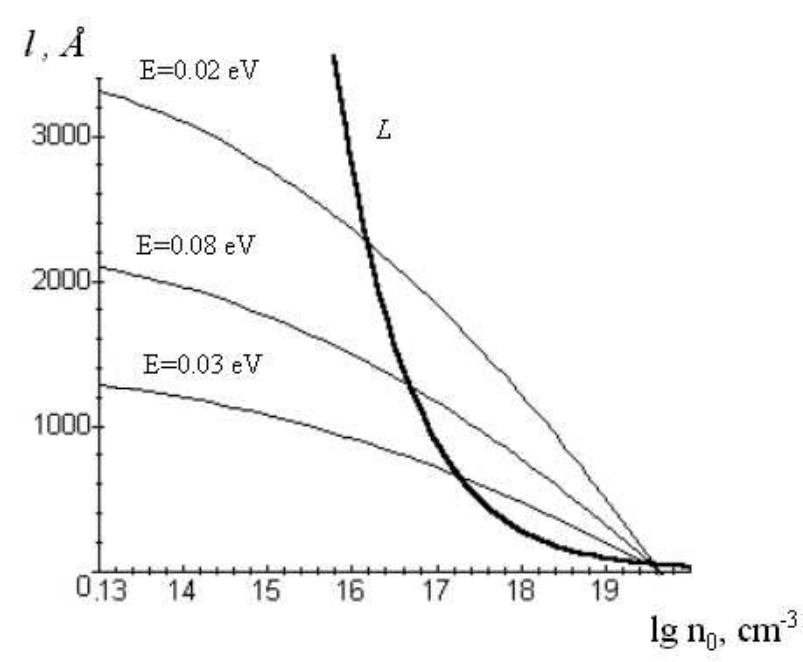

Fig. 2. Dependence of both the mean free path $l$ and width of the depletion region $L$ on the concentration of the doping impurities $n_{0}$.

Thus one can suppose that, in the conditions of this experiment, both mechanisms of transmission of electrons - coherent and incoherent - can take place; or otherwise said, the motion of a part of electrons through RTSC can be a ballistic one. We are interested if the coherent mechanism could be dominant in the structure under study with the typical parameters. To answer this question we performed a special experiment the results of which are given further. But first let us consider the evaluation of IVC taking into account all the necessary conditions.

Let energy $E$ be calculated from the bottom of a conduction band of the semiconductor and coordinate $x$ be calculated from the metal to the bulk of the semiconductor. Calculation of the transmission rates $D(E)$ was carried out using the modified WKB procedure [4]. In accordance with the WKB approximation, the wave function of an electron in the region $x_{j}<x<x_{j+1}$ is of the form $\Psi_{j}=A_{j} F_{j}$, where

$$
\begin{aligned}
& A_{j}=\left(\begin{array}{c}
a_{j} \\
b_{j}
\end{array}\right), \quad F_{j}^{=}\left(\begin{array}{c}
\phi_{j}^{-} \\
\phi_{j}^{+}
\end{array}\right), \\
& \phi_{j}^{ \pm}(x)=\frac{1}{\sqrt{\left|k_{j}(x)\right|}} \exp \left[ \pm \int_{\xi_{j-1}}^{x} k_{j}(x) d x\right],
\end{aligned}
$$

$a_{j}, b_{j}$ are constants, $k_{j}(x)=\sqrt{2 m_{j}(\Phi(x)-E)}, m_{j}$ is the effective mass in the region $j ; x_{j}$ is are coordinates of the classical turnpoints and we have $\xi_{j}=x_{j}$ for the case of barriers with the vertical walls.

Function $\phi(x)$ represents here a potential space profile of the depletion region with the built-in DBRTS:

$$
\begin{aligned}
\Phi(x) & =\varphi(x)+V_{0}\left\{\theta\left(x-l_{b}\right) \theta\left(l_{b}+d-x\right)\right. \\
& \left.+\theta\left(x-l_{b}-d-W\right) \theta\left(l_{b}+2 d+W-x\right)\right\} .
\end{aligned}
$$

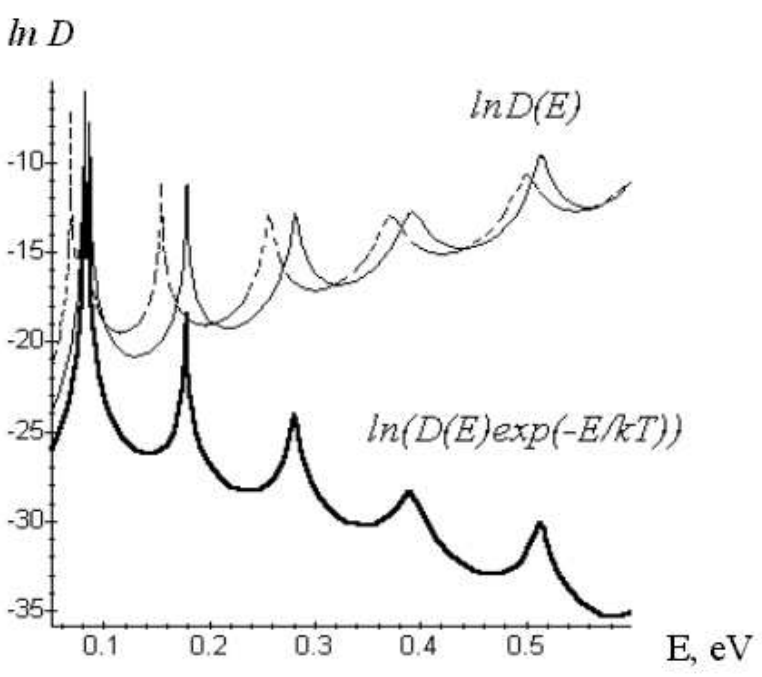

Fig. 3. Transmission rates $D$ versus electron energy $E$.

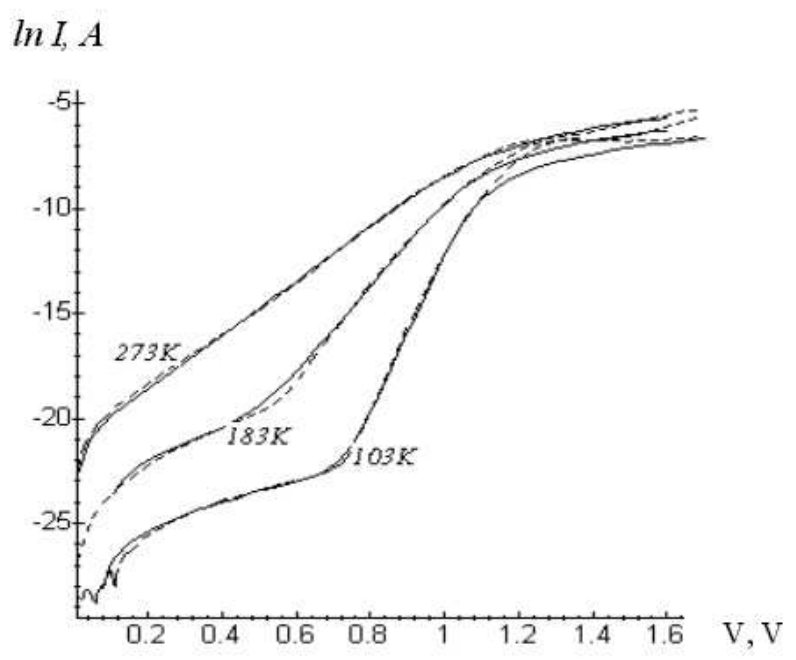

Fig. 4. Theoretical (solid lines) and experimental (dashed lines) current-voltage dependence.

Where $\varphi(x)$ is the Schottky barrier potential $\varphi(x)=$ $\frac{e^{2} n_{0}(L-x)^{2}}{2 \varepsilon \varepsilon_{0}}, d$ and $V_{0}$ the width and the height of the barrier of DBRTS respectively, $W$ is width of the quantum well.

Matrices $A_{j}$ which refer to the neighboring regions are connected with each other by the following relationship

$$
A_{j+1}=G_{j} M_{j} N_{j}
$$

where 


$$
\begin{gathered}
G_{j}=\left(\begin{array}{ll}
\frac{1}{2} g_{j}\left(1+g_{j}^{2}\right) e^{i\left(k_{j}-k_{j+1}\right) x_{j}} & \frac{1}{2} g_{j}\left(1-g_{j}^{2}\right) e^{-i\left(k_{j}+k_{j+1}\right) x_{j}} \\
\frac{1}{2} g_{j}\left(1-g_{j}^{2}\right) e^{i\left(k_{j}+k_{j+1}\right) x_{j}} & \frac{1}{2} g_{j}\left(1+g_{j}^{2}\right) e^{-i\left(k_{j}-k_{j+1}\right) x_{j}}
\end{array}\right), \\
g_{j}=\left(\frac{m_{j+1}}{m_{j}}\right)^{1 / 4}, M_{j}=\left(\begin{array}{cc}
e^{-\delta_{j}} & 0 \\
0 & e^{\delta_{j}}
\end{array}\right), N_{j}=\left\{\begin{array}{cc}
T, & (d U / d x)_{\xi_{j+1}}>0 \\
T^{+}, & (d U / d x)_{\xi_{j+1}}<0
\end{array},\right.
\end{gathered}
$$

$$
T=\left(\begin{array}{ll}
\frac{1}{2} e^{i \pi / 4} & \frac{1}{2} e^{-i \pi / 4} \\
e^{-i \pi / 4} & e^{i \pi / 4}
\end{array}\right) .
$$

Here $\delta_{j}=\int_{\xi_{j}}^{\xi_{j+1}} k_{j}(x) d x$. We use Jeffrey's transformations [5] to write $T$, matrices $G$ were obtained from the condition that both the wave functions and the flux must be continuous at $x=x_{j}$. The rate of transparency is defined as

$$
D=1 /\left[\prod_{j=1}^{s} G_{j} M_{j} N_{j}\right]^{2}
$$

for the structure which incorporated $s$ interfaces.

The result of calculation of $D$ is pictured in Fig. 3 for the following set of parameters: solid lines refer to the value $n_{0}=4 \cdot 10^{18} \mathrm{~cm}^{-3}$, the broken line $n_{0}=6 \cdot 10^{18}$ $\mathrm{cm}^{-3}, d=40 \AA, W=35 \AA$, the distance from the metal to DBRTS $l_{b}=200 \AA$ and other parameters equal those used in the experiment performed (see further).

The fat line describes the integrand in (1) for room temperature. It is seen clearly that the main contribution to $D(E)$ is due to first(lowest in energy) resonant level which locates energetically near the resonant level of DBRTS.

Thus using expressions (1), (7) one can calculate the resonant-tunneling ("low-energetic") part of the whole current.

The calculation of the above-barrier part of current can be carried out using formula (1) as well and we have now:

$$
D(E)=D_{r} \theta(E-\varphi(0)),
$$

where $D_{r}$ is the transmission rates for the isolated DBRTS.

To compare the theoretical formulae with the experimental data one must take into account the resistance of a bulk of the semiconductor $R_{b}$ so that the quantity $\varphi(0)$ equals $\varphi(0)=\varphi_{0}-e\left(V-J R_{b}\right)$, where $J$ is the whole current and the procedure of the calculation of current is a self-consistent one.

Describing the experiment performed we must note the following. For most values of external voltage DBRTS was located at the edge of a depletion region so that the resonant level was fixed in respect to the bottom of the conducting band of a semiconductor. It allows us to simplify the IVC obtained and hence its analysis becomes somewhat simpler as well. Note that the structure considered is a 3 -barrier one in fact.

The samples used for the study were grown by molecular beam epitaxy using Varian GEN II system. The structures were started from a (100) substrate with the $300 \mathrm{~nm}$ $n$-GaAs buffer layer in which the impurity concentration $n_{0}$ was $4 \cdot 10^{18} \mathrm{~cm}^{-3}$. Then another high quality layer $n$ GaAs $(150 \mathrm{~nm})$ was grown at the beginning of the Schottky layer at temperature the $540^{\circ} \mathrm{C}$. The following $4 \mathrm{~nm}$ $\mathrm{A}_{0.35} \mathrm{Ga}_{0.65} \mathrm{As}, 3.5 \mathrm{~nm}$ GaAs and $4 \mathrm{~nm} \mathrm{~A} 1_{0.35} \mathrm{Ga}_{0.65} \mathrm{As}$ undoped layers formed a resonance-tunneling barrier system. Then another $20 \mathrm{~nm} n$-GaAs high quality layer was grown before Au Schottky diodes with the size $4 \cdot 10^{-4}$ $\mathrm{cm}^{2}$ having been formed. To prepare mesa structure our samples were etched. The value of serial resistance $R_{b}$ $\mathrm{kOhm}$ was calculated from the experimental $\mathrm{I}-\mathrm{V}$ curves at sufficiently large external voltage.

The experimental dependences of the whole current on external voltage are plotted by the broken lines in Fig. 4; the three curves correspond to different temperatures $103 \mathrm{~K}, 183 \mathrm{~K}, 273 \mathrm{~K}$.

When analyzing the curves pictured we draw attention first of all to the fact that there is a region with the negative differential resistance. It proves that, indeed, we deal here with the resonant tunneling of electrons in this experiment. The other important special feature of the curves plotted is that they reveal two regions with obviously different slopes. A comparison of the theoretical formulae with experimental data shows that these experimental curves agree perfectly with the theoretical curves provided that the coherent tunneling is realized in the experiment performed. The regions before the flex point (for the temperatures $T=103 \mathrm{~K}$ and $T=183 \mathrm{~K}$ ) are corresponding to the resonant-tunneling current. The double resonance taking place here (resonant levels of a depletion region are close to those of DBRTS). Regions behind the flex point (larger bias) are associated with the over-barrier current that becomes dominant in these regions. At the room temperatures (curve 3), the abovebarrier current prevails the resonant-tunneling current practically in the whole range of external voltage. 
Summing up, we have demonstrated - both theoretically and experimentally - that the coherent mechanism of transmission of electrons can be realized and can be dominant in a specific semiconductor structure RTSC. This conclusion is important for the experiments investigating the effects of the steep non-linearity in current- voltage dependence, such as described in $[1,2]$.

We would like to express our gratitude to the Fundamental Research State Foundation of the Ministry of Education and Science of Ukraine (grant M/175-2007) for their support of this work.
[1] A. M. Korol, O. V. Tretyak, D. T. Sheka, Phys. Status Solidi 188, 1169 (2001).

[2] A. M. Korol, O. V. Tretyak, D. I. Sheka, Low. Temp. Phys. 26, 849 (2000).

[3] S. M. Sze, Physics of Semiconductor Devices (J. Wiley \&
Sons, New-York, 1981).

[4] V. N. Dobrovolsky, D. I. Sheka, B. V. Chernyachuk, Surf. Sci. 397, 333 (1998).

[5] N. Froman, P. O. Froman, JWKB Approximation (NorthHolland Publ. Co., Amsterdam, 1965).

\title{
КОГЕРЕНТНЕ ТУНЕЛЮВАННЯ В НАПІВПРОВІДНИКОВІЙ СИСТЕМІ: ДВОБАР'ЄРНІЙ ТУНЕЛЬНО-РЕЗОНАНСНІЙ СТРУКТУРІ, ВБУДОВАНІЙ У БАР'ЄР ШОТТКІ
}

\author{
Ш. Д. Лін ${ }^{1}$, Ч. П. Лі ${ }^{1}$, В. В. Ільченко ${ }^{2}$, Д. І. Шека ${ }^{2}$, О. В. Третяк ${ }^{2}$, А. М. Король ${ }^{3}$, І. В. Носенко \\ ${ }^{1}$ Факультет електронної інженерї, Націоналъний Чіао-Тунгсъкий університет, \\ проспект Та Суе, 1001, Сінчу, Тайвань, Республіка Китай \\ ${ }^{2}$ Радіофізичний факулътет, Київсъкий національний університет імені Тараса Шевченка, \\ вул. Володимирсъка, 64, Київ, Україна \\ ${ }^{3}$ Кафедра фізики, Начіональний університет харчової промисловости, \\ вул. Володимирсъка, 68, Київ, Україна
}

Досліджено резонансне тунелювання електронів у двобар'єрній тунельно-резонансній структурі, вбудованій у бар'єр Шотткі. Показано, що в цій системі може бути когерентне тунелювання; для цього випадку обчислено й проаналізовано електронний коефіцієнт прозорости та вольт-амперну характеристику. Теоретичні розрахунки дуже добре узгоджуються з даними, отриманими зі спеціяльно поставленого експерименту. 